\title{
Language awareness and
}

\section{communication as part of teacher education at the University of Pretoria, South Africa}

"Whenever children are being encouraged to predict or to offer hypotheses in maths, science, or technology; when they are asked to reflect on the impact of a piece of music or art; when they enter into imaginative empathy with characters in history or compare people's lives throughout the world, they are using language in one form or another to hammer out ideas - whether through talking, writing or reading. Each area of the curriculum offers different opportunities and challenges for extending language experience" (Bearne, 1998:1).

A B S T R A C T Teacher language proficiency is central to proficient in the medium of instruction the likelihood of a learner experiencing success is minimal. Within the South African context the majority of teachers (and learners) are not home language speakers of English and thus ensuring teacher proficiency to teach through the medium of instruction is vital. Success in the classroom depends on the teacher's discourse and interactive skills, and requires effective communication skills and a high level of language proficiency. Teachers need to be aware of the importance of language in their classrooms, regardless of which subject or learning area they teach.

To address the issue of teacher language proficiency, the University of Pretoria requires all students in the BEd programme to complete a one year module dealing with teacher language awareness. This module, entitled “Language across the Curriculum' (JTK 200), is for some students teachers the only exposure to teacher English language awareness. It is, indeed, questionable if a single year module can address the entire scope of teacher language awareness. This article focuses on the issues surrounding teacher English language proficiency and the design of the theoretical aspects demonstrated through community engagement projects as constituted in the current JTK 200 module.

This article addresses issues of course design and development with regards to teacher language proficiency, what has been learned thus far and how this will be incorporated into future offerings of the course.

Keywords: teacher training, language across the curriculum, medium of instruction, community engagement, teacher language proficiency, course design. 


\section{Introduction}

Language proficiency is generally regarded as the ability to effectively communicate in the target language by using all four skills (reading, writing, speaking and listening) as mediating tools (Dippenaar, 2004:7). Though general language proficiency serves as a basis for communicating in day-to-day activities the type of proficiency required by teachers goes beyond this general language proficiency to include elements of subject specific language proficiency and interpersonal language proficiency (Elder, 2001: Uys, 2006:55). The avocation of courses which focus on developing the necessary language proficiency required by teachers is not new (Johnson, 1990, Plüddemann, 2002:61, Uys, 2006, Van der Walt, 2010:334) but exactly the nature of such a course is still topic open for debate.

When considering the nature of a language proficiency course which focuses on teacher development and language use in the classroom, the issue of who is actually responsible for teaching language skills to the learner in the classroom must be raised. The conundrum surrounding the responsibility for language teaching pits the traditional view that language teaching is the responsibility of the language teacher against the attaché 'every teacher is a language teacher'. O'Toole (2003:6) remarks that language development has always been seen as the responsibility of the English teacher. However, the distinctive content of other school subjects and the importance that language plays in the learning process across all learning areas implies that every teacher has a vested interest in effective literacy (Goodwyn \& Findlay, 2003:27). Research undertaken by Uys, Van der Walt, Van den Berg and Botha (2007:72) found that though $66 \%$ of subject teachers interviewed regarded language teaching as their responsibility only $47 \%$ indicated that they practice this in their classrooms. The importance of adequately preparing all teachers (and not just language teachers) to use the four language skills is highlighted by Short (2002:18) who states that learners who are taught by teachers that successfully use the four language skills and who promote the development of functional language skills, have much improved prospects of attaining academic literacy. Indeed, Uys et al (2007:69) comment that the failure of subject teachers to teach functional language skills may be a fundamental reason for learners' lack of academic achievement.

To address this, the BEd programme at the University of Pretoria includes the module "Language across the Curriculum" (JTK 200) which is a compulsory second year module focussing on language barriers and language issues students may encounter in the classroom when teaching through the medium of English. The module is presented in English only and is often the only module students take through the medium of English as students can choose to take the rest of the curriculum in English or Afrikaans. There are currently 746 students enrolled for the module and students attend class once a week for 50 minutes in 5 separate groups.

This is the only module that prepares students for the language challenges they may experience in the classroom in their specific learning area, whether that be sciences or history, ranging across the spectrum of all learning areas and all phases. The module has a twofold purpose which is to enhance the English language proficiency of the students and to prepare them for communication and cultural barriers they may encounter in their classrooms. The question was to decide what content should be addressed in the limited time available to ensure that the needs of all students in this diverse group will be addressed and they are adequately prepared for the envisaged language challenges experienced by their learners as well as their own. 
Currently the University of Pretoria is undertaking a review of the BEd curriculum and what follows is a discussion and reflection on issues surrounding teaching English language proficiency as inherent to the design of both the theoretical and community engagement aspects which constitute the current JTK 200 module. The outcome of this discussion will serve to inform the new curriculum. This study touches on issues of language course design and development and aims to raise awareness surrounding the importance of including a teacher language proficiency module in the training of teachers. Though limited to a single course at a single university the issues raised may well be applicable to other situations where the issue of teacher language proficiency is being explored.

\section{The language situation in the South African classroom}

To understand more fully the role of language in education in South Africa, one has to take a brief look at the current language situation in schools. According to the South African Census (2001) English as a home language is spoken by only $8.2 \%$ of the population yet English has become, 'the major language of communication for business, government and education' (Singh, 2009:285). Currently, 22\% of Grade 1's are taught through the medium of English, in Grade 4 this number increases to 79\% (De Wet, 2002:119; DoE, 2010:16) and again increases to $81,4 \%$ by Grade 12 (Afrikaans constitutes the other $12,8 \%$ and the other official languages, 5.8\%). This has resulted in English becoming the dominant medium of instruction at most educational institutions (Uys et al, 2007:69; Singh, 2009:282; Desai, 2001:326; Foley, 2002:53). As a consequence, an overwhelming number of learners are being taught in a language other than their home language (Wildsmith-Cromarty \& Gordon, 2009:361; Uys, Van der Walt \& Botha, 2005:322) and often by teachers not adequately prepared to teach through the medium of English (Evans \& Cleghorn, 2010:147; Foley, 2002:54; Heugh, 2009:97, Sookrajh \& Joshua, 2009:334).

Of major concern is the reported drop in literacy levels among learners applying for university study. A study reported on by Uys (2006:7) found that in $199820 \%$ of learners who applied for bursaries for tertiary studies could read and write on an appropriate level, however in 2005 this number had dropped to $12 \%$. This reported drop in literacy impacts on the wider university system with some programmes offering extended programmes, intensive bridging courses and courses focused specifically on academic English proficiency.

\section{Teacher proficiency and language of instruction}

The status of English proficiency has a wider, deeper impact on teacher training programmes as teacher language proficiency requires a strong foundation in general language proficiency before interpersonal and subject specific competencies in the medium of instruction may be developed (Uys, 2006:58). Development of these competencies, especially when the student is a second language speaker of English, is not a quick process. Uys (2006:111), in concluding on her study, recommends that language modules which focus on teacher proficiency in the undergraduate programme should be run for at least 3 years. However, teacher language proficiency can only be addressed once general language proficiency has been obtained.

The importance of English in the classroom implies that teachers must have a very good command of the medium of instruction (English) to ensure that effective teaching and learning 
take place (Mafisa \& Van der Walt, 2002:23). The ability to use English effectively in the classroom requires specific competencies, which is not necessarily developed through general English programmes, syntactic competence or social fluency (Kilfoil, 1999:51). Defining the language proficiency requirements for teachers is not a straightforward task. Elder (2001:152) explains that the proficiency required by teachers 'encompasses everything that 'normal' language users might be expected to be able to do in the context of both formal and informal communication, as well as a range of specialist skills.'

Hugo and Nieman (2010:60) state that where a second language is used as a medium of instruction by a teacher who is a second language speaker of the language, the ability to use the four language skills, knowledge about language use and culture and an understanding of how second languages are learned and acquired are paramount for a successful learning environment.

In her study, De Klerk (1995:8) interviewed several teachers on language matters in their schools. Teachers admitted that they could not help their learners as they were not proficient in English themselves and experienced difficulties in understanding reading material prescribed for their learners. The lack of adequately proficient teachers to teach through the medium of English has been cited as one of the major barriers to effective learning (Plüddemann, 2002:48; Uys et al, 2007:69; Sookrajh \& Joshua, 2009:334, Evans \& Cleghorn, 2010:141; Hugo \& Nieman, 2010:61). The link between teacher proficiency and the academic success of learners is discussed by Uys et al (2007:77), who comment that effective teacher training in the medium of instruction (which in most cases is English) is one of the most important factors in improving the level of academic literacy in South African learners.

\section{The importance of adequate teacher preparation in the medium of instruction}

The assertion that proficient teachers are paramount for the success in the classroom and the need to ensure teachers receive adequate preparation during their studies is not a recent development. Johnson (1990:269) states, 'a course which focuses on the effective use of classroom specific language should be an important part of any teacher preparation course, but is most critical where teachers will be teaching through an additional language'. What is worth noting is that although the importance of adequately preparing teachers to teach through the medium of instruction has been advocated for over 20 years currently no mandatory requirement for ensuring teacher language proficiency is required in South Africa. This issue has been discussed in research with numerous researchers recommending the re-introduction of mandatory preparation courses as well as mandatory endorsements of teacher proficiency (Evans \& Cleghorn, 2010:147; Plüddemann, 2002:61)

The aim of teacher language proficiency is not necessarily the attainment of near-perfect L1 proficiency but rather to achieve a 'threshold proficiency' level which would enable a teacher to teach effectively in English (Richards, 2010:103). This 'threshold proficiency' is not an 'eitheror' proposition but must rather be viewed as a continuum with varying degrees of developing proficiency (Pasternak \& Bailey, 2004:163). Elder (2001:162) observes that a high level of language proficiency does not necessarily imply a better teacher; on the contrary, a teacher who speaks at a lower level of linguistic complexity and explains in simpler terms to second-language learners may achieve better results. Simplicity, clarity and sensitivity to the audience are of more value 
than elaborateness (Elder, 2001:162). Student teachers should rather be trained in the ability to present subject-specific content, discourse competence, command of linguistic features such as directives and questioning, and simplification strategies (Elder, 2001:152).

In addition to these elements, teachers need to be trained in the theory of language development and learning (Andrews, 2007:ix), nonverbal behaviour and speech, second-language acquisition processes and cultural issues (Klaassen \& De Graaff, 2001:390), technical vocabulary, the reading of official documents, professional journals and students' compositions (Riegelhaupt, 1994:95), the sourcing of target language resources, reflection strategies for monitoring own language usage, and consistent providing of feedback on learners' language usage (Richards, 2010:103).

According to Darling-Hammond and Bransford (2005:161), the language education of teachers must become one of the basic strands of teacher preparation-parallel to courses in human development, teaching and learning. Such a course should include an introductory course in linguistics that focuses on questions, oral language development, reading and writing (DarlingHammond \& Bransford, 2005:161). Student teachers need to understand how language works, what it means to understand a language, and how language is used in everyday life. This knowledge can be applied to the particular learning areas that they are going to teach. For example, they must examine how language is used in their learning area (for example, maths and science) and what subject jargon is particular to that area. In addition to a specific course on language use, these aspects should be incorporated into and stressed continuously throughout the student teacher's curriculum.

\section{Teacher training in the medium of instruction at the University of Pretoria}

When students enter the University, one way used to analyse their general language proficiency in English is to look at the results they achieved during their final examination in secondary school (grade 12). All learners write the national examination, which is a standardised examination written in all the provinces of South Africa. Learners can write the examination in English as a first language (L1) or English as a second language (L2).

The grade 12 results for English of the students enrolled for JTK 200 in 2011 indicate that their language ability averages 68\% (see Tables 1 and 2).

Table 1: Grade 12 results of candidates who passed English as $L 1$

\begin{tabular}{|c|c|}
\hline \multicolumn{1}{|c|}{ Results } & Number of candidates \\
\hline A & 19 \\
\hline B & 60 \\
\hline C & 104 \\
\hline D & 58 \\
\hline E & 2 \\
\hline
\end{tabular}

Average: $65.99 \%$

The results of the group who took English as L2 show that eighty four students averaged below $60 \%$. These marks reflect only the general English language ability of students, and not their academic language proficiency or their ability to communicate as teachers which requires rather complex language proficiency. On the other hand, there are more than 600 students 
Table 2: Grade 12 results of learners who passed English as $L 2$

\begin{tabular}{|c|c|}
\hline \multicolumn{1}{|c|}{ Results } & Number of candidates \\
\hline A & 73 \\
\hline B & 215 \\
\hline C & 176 \\
\hline D & 80 \\
\hline E & 4 \\
\hline F & 0 \\
\hline
\end{tabular}

Average: $69.179 \%$

who have good language ability and do not need specific instruction in basic language skills. Any language module must be designed in such a way as not to frustrate either the stronger or weaker students in the group, and yet cater for all or most of the students' language needs.

A survey was conducted among JTK 200 students and lecturers at the beginning of 2010 . This survey consisted of 25 questions and was done to determine the perceptions of students and lecturers on the students' English language proficiency and needs. The survey included both quantitative and qualitative questions and was done to assist the lecturer in modifying the JTK 200 module. The survey showed that 73,24\% of the students are second-language speakers of English and 1,99\% are third-language speakers. Only 24,77\% speak English as their first language. Most of the students focus on Languages (271) and Natural Sciences (206). $61,22 \%$ of the students feel that their conversational skills in English are reasonably good, while $30,38 \%$ feel these skills are very good. They feel they are more competent in speaking English than the lecturers perceive them to be. Similar questionnaires distributed to lecturers, indicate that they feel at least $40 \%$ of the students have a poor or very poor conversational proficiency in English.

According to the surveyed students, the most significant problem that students and lecturers identified with regard to English proficiency is the ability of the students to write academic research papers and essays. However, the students indicated that they do not need extra modules, but rather more opportunities to practise these skills. The majority of students $(88 \%)$ feel that their English academic language ability is reasonable to very good, whereas the lecturers indicated that only $30 \%$ of the students have good English academic language ability.

Such differences in perceived proficiency are not anomalous. Though focussing specifically on Black South African English Coetzee-Van Rooyen and Verhoef (2000) and Coetzee-Van Rooy and Van Rooy (2005:13) both report on the 'misplaced' perception of participants' demonstrated proficiency and what they believe their proficiency to be. Coetzee-Van Rooy and Van Rooy (2005:13) explain that this possible difference between perceived English proficiency and demonstrated English proficiency "can be interpreted in terms of a "wish," rather than a realistic match...'

The discrepancy between lecturers' perceptions and students' perceptions was explored by Killen, de K Marais and Van Z Loedolff (2003:147) in a study focussing on perceived factors resulting in success and failure at university. When asked to rank the importance of being able to read in the language of instruction as a factor for success at university, lecturers ranked this 
2nd overall while 3 rd year students ranked it 12 th out of a possible 38 places. In terms of writing the language of instruction, lecturers ranked this 3rd and students 14th out of a possible 38 places. When asked to rank poor literacy skills as a possible cause for failure, lecturers ranked this as 4th while 3rd year students ranked it 34th out of a possible 38 . What can be gleaned from this is the possibility that students do not view language proficiency as key to academic success and that could explain why they feel that their current language proficiency suffices.

The purpose of the JTK 200 survey was, however, not to evaluate the students' language proficiency, but to analyse the potential English language needs of the students and the anticipated language issues they need to be prepared for. In a further attempt to analyse the potential language needs of beginner teachers, the different functions and roles of teachers were discussed with the second-year student teachers during lectures.

From these discussions it was concluded that a teacher operates in four different contexts: on an individual level, in the classroom, in the school, and in the community (see Figure 1). For example, in an individual context the teacher needs language competence in order to prepare lesson plans and teaching material, design activities or set examinations. In the classroom, the teacher needs to communicate with learners, explain concepts or manage the classroom. In the school, teachers communicate with colleagues, attend meetings and discuss school matters. In the community, teachers communicate with government officials, parents or sponsors.

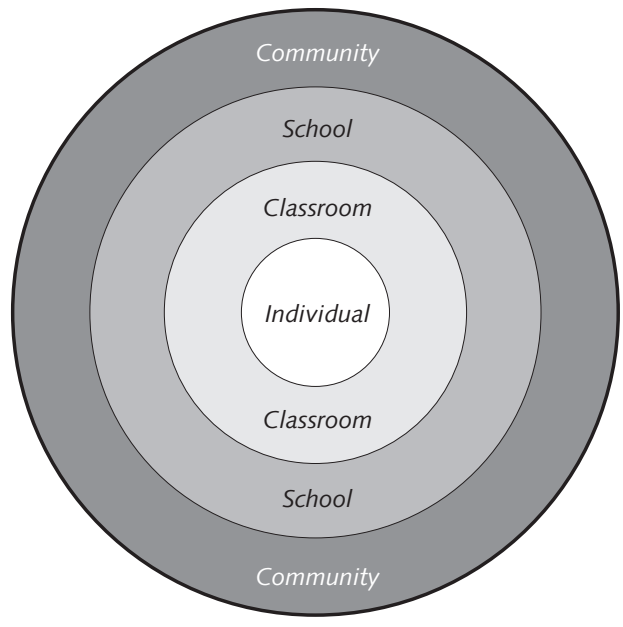

Figure 1: Levels on which a teacher operates

To structure these language needs identified by the students, the lecturer decided to look at the roles of the teacher as identified by the Norms and Standards for teachers prescribed Department of Education (DoHET, 2010:51). The Department of Education has identified seven roles to be fulfilled by teachers. These are:

- mediator of teaching and learning

- interpreter and designer of learning programmes

- manager, administrator and leader

- scholar, researcher and lifelong learner

- learning area specialist

- assessor

- member of the community who has to fulfil a pastoral role.

From the discussions mentioned and by incorporating ideas from research as indicated earlier it seems that students have to be familiar with the theory of language acquisition and communication and the skills of using language in the classroom while simultaneously improving their own language proficiency. Any module aimed at enhancing students' ability to use language in the classroom needs to include all three aspects. Therefore these elements were integrated with the needs identified above to form the curriculum of the language awareness module called "Language across the curriculum".

The lecturer compiled a list of language-related elements in the literature considered to be essential for student teachers, as discussed earlier in this article. These were used to design 
the outcomes of the module. As future educators, students need to understand what effective communication is and how to deal with the many communication situations that arise in the teaching profession. Furthermore, the module concentrates on the skills and knowledge teachers need to communicate in English. After completing the module, students have to show an understanding of the unique role of language in education. A further requirement for passing the module is an ability to demonstrate the use of teacher language proficiency in English in their own learning areas.

The course content aims to give students a thorough theoretical background on various reallife situations in which they will need to communicate effectively using both the written and spoken word. It also aims, at a practical level, to assist students in improving their own interpersonal communication skills. Based on all the literature review discussed above, student surveys, class discussion and own teaching experience over 30 years, the lecturer identified the following basic themes to be included in the module "Language across the curriculum":

\section{Communication}

Students need to demonstrate an understanding of the elements of a communication model and related terminology, and need to be aware of the theory behind communication in general.

\section{The relation between cognitive development and language}

Students need to be aware of the importance of cognitive skills in relation to language development.

\section{The relation between culture and communication}

Students need to demonstrate an understanding of issues such as second-language acquisition, language policy, multiculturalism, multilingualism, gender, register, tone, language varieties and dialect.

\section{Communication barriers}

Students have to find innovative ways to enhance communication in different contexts and to overcome communication barriers. Non-verbal communication and body language are also to be addressed.

\section{Effective communication at all levels on which a teacher operates within each teachers' role}

Students examine communication at the individual level, in the classroom, in the school and in the community, while simultaneously integrating the seven roles of the teacher effectively, using all four language skills (reading, writing, speaking, listening).

\subsection{Role as a mediator}

In the classroom: Students have to demonstrate innovative ways to enhance communication in different contexts and overcome communication barriers. Classroom discussion, interaction, correct use of language, giving instructions, asking questions and giving feedback to answers are dealt with. Students look at group work, pair work, individual learning and class discussions 
and how to encourage learners to use the target language effectively and, use mind maps, summaries and brainstorming techniques.

In the school: How to organise information evenings, debates, and speech competitions, and to facilitate sport.

\subsection{Role as a learning area specialist}

In the classroom: Students have to be able to demonstrate valid interpretation of visual information, and to interpret and apply graphs, bar charts, pictograms, diagrams and tables in their specific area of teaching and learning. Issues such as subject jargon, subject-specific issues and where to find information on their own subject are addressed. The planning and application of teaching in a specific learning area are discussed.

\subsection{Role as an interpreter and designer of programmes and materials}

Students have to be able to read, analyse and interpret appropriate learning material in their own content area, as well as prepare and present lessons, using language correctly. Students have to show how to use teaching resources such as newspapers and brochures.

In the school: Students have to be able to write minutes, faxes, notices, memos, notes, formal and informal letters, and organise an event in the community.

\subsection{Role as leader, administrator and manager}

Students discuss issues such as how to manage self, apply for a job, write a CV and a letter of application, go for an interview, manage time, and use electronic mail.

In the classroom: Students have to be able to keep records, file documents accurately, give feedback, assess learners, set questions and exam papers, and write notes.

In the school: Students have to be able to organize school functions, use correct etiquette, make announcements, draft advertising brochures, pamphlets, notices, correspondence, transactional writing, and official documents, as well as organise and conduct meetings in English.

\subsection{Role as scholar, researcher and lifelong learner}

Students have to be able to conduct research in their subject area, write research reports and incorporate the latest trends in their area of learning in the classroom. They need to demonstrate the ability to reflect on their own teaching practices and apply research.

\subsection{Develop and apply communication skills as pastoral role}

Students have to be able to act responsibly and empathetically towards self, learners and colleagues, and they have to be able to communicate appropriately in a school setting and in the community.

\subsection{Role as assessor}

Students have to be able to set exam questions and memoranda correctly and furthermore they should be able to set assessment criteria and indicate the relevance of language.

\section{Application of required skills in community engagement projects}

In an attempt to internalise the theory discussed in the lecture hall, it was decided to include

a community engagement project in 2007 , where students would have the opportunity to 
practise their communication skills in a real life situation. The purpose was to give students an opportunity to apply the outcomes of the course in an authentic situation and expose them to their pastoral role as teachers. Thus, a partnership was formed with the Thuthukani project which runs at a local primary school in a township outside Pretoria. The Thuthukani project has been in existence for the past three years and gives opportunity to social work students to practise skills required in their curriculum. This project already had a partnership with two primary schools in Mamelodi, where the social work students assist children with their schoolwork and teach them additional life skills. These third-year social work students are doing their practical training, yet they do not have training in teaching and find it difficult to help the children adequately. Their lecturer approached the Faculty of Education and a partnership was formed.

The JTK 200 students were asked to assist the learners with their schoolwork under the supervision of the third-year social work students. Due to the success of the project in 2007, other similar projects were selected and partnerships established. Currently the JTK students tutor learners for 30 hours at 42 projects in disadvantaged areas, varying from afterschool centres, primary schools and schools for juvenile delinquents in two prisons around Pretoria. Students are familiarised with the projects through discussions and videos in the beginning of the year. They then choose a project which is suitable to their interests, learning area and the age group that they are planning to teach. The University of Pretoria arranges bus transport for students to most of the projects. The students have the option of joining these projects, or to apply to do similar projects in their own communities, subject to the revision and approval of the lecturer.

The question arises whether these projects address the outcomes for the JTK 200 module and whether it provides opportunities for students to develop their teacher English language proficiency and communication skills.

\section{Outcomes of JTK 200 linked to community engagement.}

Based on the outcomes listed above, the following activities were designed to provide students the opportunity to demonstrate practically the attainment of these outcomes. At the commencement of the academic year students decide which project they would like to participate in and which is appropriate to their learning area and phase. Thereafter they write a proposal, letter of application and include their curriculum vitae in a formal application to the project of their choice. After this has been assessed and approved by the lecturer, they start their orientation on the specific project.

Students must keep a record of all communications between themselves and the service providers before and during the project. They have to write weekly reflections on the experience and the progress of the learners. These reflections are discussed during lectures. Finally, at the end of the year, students have to compile a complete portfolio on the project, which has to include all correspondence, documentation and proof of the work they did, examples of the children's progress, and a final report and reflection on the project. They have to do a final multimodal presentation, during which they are assessed on their speaking and presentation skills, as well as on the progress and evaluation of the project. 
They have the opportunity to apply the theory on communication models and interaction in a real life situation. They experience hands on how cognitive development is influenced by language development as many of the learners they work with, do not speak English although that is the supposed medium of instruction in their schools. This forces the students to think on their feet and design activities to communicate with the learners. They make use of sign language, pictures, volunteers or translation and find solutions to their own individual problems.

The students see and experience cultural and communication barriers and have to find solutions in order to complete their projects. They may seek advice from their methodology lecturers or consult with other students. In addition they had to participate in an on line website called "Communityteam.org" where they took part in discussions on the problems they encountered and provided suggestions and solutions to one another.

All the above provided the students with opportunities to enhance their own teacher English language proficiency, as required by the course. They operate in the classroom, in the school context, in the communities and have to plan and reflect for these opportunities on an individual level. They address all the roles of a teacher as set out in the outcomes, as they have to mediate with the learners, be learning area specialists, design their own activities and assess their learners before and after the intervention. All of these activities they have to administer and manage themselves, while simultaneously addressing the pastoral role. They are required to do adequate research on the learners' context and the project itself.

Although they still write a formal examination in November, the community engagement project provides the lecturer with ample opportunity to teach, practise and assess the skills that the students need to acquire during the module. Examination questions consist of theoretical as well as applied and integrated questions, which include issues regarding culture, language policy, teaching and learning, and assessment.

\section{Conclusion}

The current module in "Language across the curriculum", offered at the University of Pretoria, aims to make students aware of the language issues that have to be addressed in the classroom, while simultaneously (though indirectly) addressing the students' own language proficiency. The implementation of community engagement tutoring projects provides opportunities for students to apply the theoretical principles in an authentic context and to experience real-life communication issues in an educational context. Student reflections and feedback show that students benefit very much from the experience and feel that they have a better understanding of the challenges in the field.

However, students feel there is still a gap between theory and practice. They would like to see an even closer link between the community engagement projects and the theory addressed in lectures. The module will be revised again in an attempt to incorporate challenges experienced by the students at the projects within the theoretical framework of the module. Lectures should consist of class discussions on problems encountered with communication in the authentic situations the students find themselves. That would mean that the theoretical principles could be addressed in self-study projects, research assignments and on-line quizzes, and class time could be spend much more effectively by discussing problems experienced by students in authentic contexts. 
It may be concluded that more research needs to be done on the effectiveness and impact of a module on language awareness as a means of improving the language component of the student teachers' curriculum. Currently impact studies are being done on the effect of the community engagement projects on students as well as the learners they work with.

Language challenges in the classroom remains a very important issue, especially in a multilingual country such as South Africa and should form an essential part of teacher training.

\section{BIBLIOGRAPHY}

Andrews, S. 2007. Teacher Language Awareness. Cambridge: Cambridge University Press.

Bearne, E. (ed.). 1998. Use of language across the primary curriculum. London: Routledge.

Central Statistical Services. 2001. South African Census: 2001. Available from: www.satssa.gov.za. (Accessed 1 August 2010).

Coetzee-Van Rooy, S. and Van Rooy, B. 2005. South African English: labels, comprehensibility and status. World Englishes, 24(1):1-19.

Coetzee-Van Rooy, S and Verhoef, M.M. 2000. Perceptions of English Proficiency: views from Southern Sotho Speakers. South African Journal of Linguistics, 38(1):163-185.

Darling-Hammond, L. and Bransford, J. (eds.). 2005. Preparing teachers for a changing world. San Francisco: John Wiley and Sons.

De Klerk, G. 1995. Slaves of English. In: Heugh, K., Siegruhn, A. and Pluddemann, P. (eds.). Multilingual education for South Africa. Isando: Heinemann.

Department of Education. 2010. The status of the language of learning and teaching (LOLT) in South African schools: A quantitative overview. Pretoria: Department of Education.

Department of Higher Education and Training. 2010. Draft Policy on the Minimum Requirements for Teacher Educations selected from the Higher Education Qualifications Framework (HEQF). Retrieved from: http://www.dhet.gov.za/LinkClick.aspx?fileticket=x\%2Fq3U3\%2F0qSo\%3D\&t abid $=36 \&$ mid $=1071$

Dippenaar, A.J.F. 2004. The Vista University English Language Proficiency Course: An Evaluation. Doctoral Dissertation. Potchefstroom: Potchefstroom Universiteit vir Christelike Hoër Onderwys.

Desai, Z. 2001. Multilingualism in South Africa with particular reference to the role of African languages in education. International Review of Education, 47(3):323-339.

De Wet, C. 2002. Factors influencing the choice of English as language of learning and teaching (LoLT) - A South African Perspective. South African Journal of Education, 22(2):119:124.

Elder, C. 2001. Assessing the language proficiency of teachers: are there any border controls? Language Testing, 18(2):148-170.

Evans, R. \& Cleghorn, A. 2010. 'Look at the balloon blow up': Students teacher-talk in linguistically diverse Foundation Phase classroom. Southern African Linguistics and Applied Language Studies, 28 (2):141-151.

Foley, A. 2002. South African Education and the Dilemmas of Multilingualism. English Academy Review, 19(1):51-64.

Goodwyn, A. and Findlay, K. 2003. Shaping literacy in the Secondary School: practice in the age of the national literacy strategy. British Journal of Educational Studies, 51(1):20-35.

Heugh, K. 2009. Contesting the Monolingual Practices of Bilingual Policy. English Teaching Practice and Critique, (8): 2 96-113. 
Hugo, J. and Nieman, M. 2010. Using English as a second language of instruction: Concerns and needs of primary school teachers in South Africa. Journal for Language Teaching. 44(1):59-69

Johnson, K.J. 1990. Developing teachers' language resources. In Second language teacher education. Edited by: Richards, J.C. \& Nunan, D. Cambridge: Cambridge University Press.

Kilfoil, W. 1999. The linguistic competence of science students. South African Journal of Higher Education, 13(1):46-55.

Killen, R., de K Marais, A. and Van Z Loedolff, P. 2003. Success and failure in distance education: perceptions of South African students and lecturers in Business Management. South African Journal of Higher Education, 17(2):147-158.

Klaassen, R.G. and De Graaff, E. 2001. Facing innovation: preparing lecturers for English-medium instruction in a non-native context. European Journal of Engineering Education, 26(3):281-289.

Mafisa, P.J. and Van der Walt, J.L. 2002. Grammatical competence of ESL teachers. Per Linguam, 18(1):15-26.

O’Toole, J.M. 2003. Literacy across the Secondary Curriculum. Jesmond. O'Toole and Associates.

Pasternak, M. \& Bailey, K.M. 2004. Preparing non-native and native English-speaking teachers: Issues in professionalism and Proficiency. In Learning and teaching from experience: perspectives on non-native English-speaking professionals. Edited by: Kamhi-Stein, L.D. Ann Arbour: University of Michigan Press

Plüddemann, P. 2002. Action and reflection: dual-medium primary schooling as language policy realization. Perspectives in Education, 20(1):45-61.

Richards, J.C. 2010. Competence and performance in language teaching. RELC Journal, 41(2):101-122.

Riegelhaupt, F. 1994. Spanish language proficiency for bilingual teachers. Teaching and testing, 19(1):78-96.

Singh, P. 2009. Trawling through Language Policy: Practices and Possibilities post-1994. Language Learning Journal, 37(3):281-291.

Short, D. 2002. Language learning in sheltered social classes. TESOL Journal, 11(1):18-24.

Sookrajh, R. and Joshua, J. 2009. Language matters in rural schools in South Africa: are educators making the implementation of the Language in Education Policy (1997) work? Language Learning Journal, 37(3):323-338.

Uys, M. 2006. A Proposed Model for Training English Medium of Instruction Teachers in South Africa. Doctoral Dissertation. Potchefstroom: North-West University.

Uys, M., Van der Walt, J.L. and Botha, S. 2005. A scheme for training effective English second language medium of instruction teachers. Journal for Language Teaching, 39(2):321-336.

Uys, M., Van der Walt, J.L., Van den Berg, R. and Botha, S. 2007. English as a medium of instruction: a situation analysis. South Africa Journal of Education, 27(1):69-82.

Van der Walt, C. 2010. Of shoes-and ships and sealing wax: A dynamic systems approach to language curriculum orientation. Southern African and Applied Language Studies, 28(4):232-337

Wildsmith-Cromarty, R. \& Gordon, M. 2009. 'Policy versus practice: the role of the home language in learning mathematics and science in English-medium classrooms'. Language Learning Journal, 37(3):359-370. 


\section{ABOUT THE AUTHORS}

\section{A.J.F. (Hanlie) Dippenaar (PhD)}

Email: ajf.dippenaar@up.ac.za

\section{T. (Tammy) Peyper}

Email: tsalzmann@softhome.net

Humanities Education

Faculty of Education

Groenkloof Campus

University of Pretoria

South Africa 